\title{
Mortality patterns in long-term survivors of childhood or adolescent central nervous system tumour in Sweden
}

\author{
Wuqing Huang ${ }^{1} \cdot$ Jan Sundquist ${ }^{1,2,3} \cdot$ Kristina Sundquist $^{1,2,3} \cdot$ Jianguang $\mathrm{Ji}^{1}$
}

Received: 12 September 2019 / Accepted: 19 October 2019 / Published online: 1 November 2019

(c) The Author(s) 2019

\begin{abstract}
Purpose A growing number of young patients with central nervous system (CNS) tumour survived for more than five years. However, these long-term survivors might be at risk of multiple late effects thus leading to a higher risk of late mortality. We aimed to explore the risk of late mortality and the pattern of mortality among long-term survivors of childhood or adolescent CNS tumour.

Methods We identified 5-year survivors with childhood or adolescent CNS tumour before age 20 years through the Swedish Cancer Registry. Five controls were randomly matched for each patient to generate the reference group. We retrieved information about death via Cause of Death Register. We calculated the absolute excess risk (AER) of death and the hazard ratio (HR) of death using Cox proportional hazard model.

Results Long-term survivors with CNS tumour suffered a significant higher risk of overall mortality (HR 6.56, 95\% CI 5.71-7.53; AER 5.89, 95\% CI 5.03-6.87). The mortality rate declined with the increasing survival time, but it was still higher even after 30 years of follow-up. Malignant neoplasms contributed mostly to late mortality with an AER of 3.75 (95\% CI 2.95-4.75). Female survivors, survivors diagnosed at a younger age and survivors with medulloblastoma were particularly strongly associated with a higher risk of death.

Conclusions Long-term survivors of childhood and adolescent CNS tumours are at a higher risk of late mortality, and the risk of death is affected by gender, age at diagnosis and types of CNS tumour.
\end{abstract}

Keywords Central nervous system tumour $\cdot$ Long-term survivors $\cdot$ Mortality patterns

\section{Introduction}

Electronic supplementary material The online version of this article (doi:https://doi.org/10.1007/s11060-019-03321-w) contains supplementary material, which is available to authorized users.

\footnotetext{
Wuqing Huang

Wuqing.huang@med.lu.se

Jianguang Ji

Jianguang.ji@med.lu.se
}

1 Center for Primary Health Care Research, Lund University/ Region Skåne, Skåne University Hospital, Jan Waldenströms gata 35, 20502 Malmö, Sweden

2 Department of Family Medicine and Community Health, Department of Population Health Science and Policy, Icahn School of Medicine at Mount Sinai, New York, USA

3 Center for Community-Based Healthcare Research and Education (CoHRE), Department of Functional Pathology, School of Medicine, Shimane University, Shimane, Japan
Central nervous system (CNS) tumour was the first most commonly newly-diagnosed type of tumour in Swedish population before age 20 years in 2016 , with age-standardised incidence 4.7 per 100,000 person-years in girls and 3.7 in boys [1]. Due to the improvement of treatments and earlier detection, the five-year survival rate for patients with CNS tumour has dramatically increased; more than $70 \%$ of patients diagnosed with childhood and adolescent CNS tumour can survive beyond five years [2]. In clinical practice, the 5-year survival rate is commonly used as a benchmark of clinical cure, but the mortality rate, as well as the mortality patterns, among long-term survivors of childhood and adolescent CNS tumour are still largely unknown. It is thus highly necessary to explore this unanswered question by using high-quality data with high power to provide better clinical guidelines and surveillance recommendations of these survivors. Some previous studies have explored 
the overall and cause-specific mortality among long-term survivors with childhood cancers [3-10], whereas limited evidence existed on specifically investigating the patterns of death cause among survivors with CNS tumour diagnosed in children or adolescents.

In this population-based cohort study utilising a range of Swedish nationwide registers, we aimed to explore the mortality rate and the mortality patterns among long-term survivors who were diagnosed with CNS tumour before 20 years of age. In addition, we investigated whether the mortality patterns were associated with survival time and with specific types of CNS tumour.

\section{Materials and methods}

\section{Study population}

We identified all patients who were diagnosed with childhood and adolescent CNS tumour (age $<20$ years) between 1958 and 2016 from the Swedish Cancer Registry by using the 7th International Classification of Disease (ICD-7) code 193. Only primary CNS tumour was considered in the current study. The Swedish Cancer Registry was created in 1958 and is maintained by the National Board of Health and Welfare. Clinicians, pathologists, and cytologists in Sweden must report all newly diagnosed cases of cancer to the Swedish Cancer Registry separately to complement each other, which guarantees its high sensitivity and specificity [11]. Long-term survivors are defined as those patients who have survived at least five years after the diagnosis, which means that we excluded patients who died within five years post-diagnosis.

Five cancer-free individuals were matched to each patient conditional on the same birth year, gender, birth country (Sweden or abroad) and highest education (1-9 years, 10-11 years or $>11$ years). By retrieving from the Total Population Register which covers the whole Swedish population who have a residency permit and combining with the Swedish Cancer Register, individuals who did not have a diagnosis of CNS tumour during the study period and were still alive on the date of the corresponding survivors being started to follow-up were randomly selected.

The Ethics Committee at Lund University approved (February 6,2013 ) this nationwide cohort study (Dnr 2012/795). The project database is located at the Center for Primary Health Care Research in Malmö, Sweden.

\section{Ascertain of outcomes}

By linking to the Cause of Death Register, we collected death-related information, including date of death and cause of death. Causes of death were coded according to
International Classification of Disease (ICD), 7th version for deaths before 1969, 8th version for deaths between 1969 and 1986, 9th version for deaths between 1989 and 1996 and 10th version for deaths after 1996. The ICD-7, ICD-8 and ICD-9 codes were translated to ICD-10 codes to keep consistent of the underlying cause of death during the study period. The main outcome was the overall mortality. To explore the patterns of death causes, we further classified the cause of deaths into nine specific subgroups: infectious and parasitic disease (ICD-10 codes: A00-B99); malignant neoplasms (ICD-10 codes: C00-D48); endocrine, nutritional and metabolic diseases (ICD-10 codes: E00-E90); diseases of the nervous system and sense organ (ICD-10 codes: F00H95); diseases of the circulatory system (ICD-10 codes: I00-I99); diseases of the respiratory system (ICD-10 codes: J00-J99); diseases of the digestive system (ICD-10 codes: K00-K93); injury, poisoning and certain other consequences of external causes (ICD-10 codes: S00-T98); and others. To examine the temporal trends of causes of death with survival time, we divided the causes of death into two categories, neoplasm-specific death and non-neoplastic death.

\section{Assessment of exposure and covariates}

By retrieving from the Swedish Cancer Registry, we got information about the diagnosis of CNS tumour, including date of diagnosis and histology of tumours. Based on age at diagnosis of CNS tumour, survivors were classified into four categories: survivors diagnosed at preschool age (0-4 years old), primary school age (5-9 years old), preadolescent (10-14 years old) and adolescent (15-19 years old). Survivors diagnosed before 15 years old were also noted as survivors diagnosed at childhood. According to the 2016 World Health Organization Classification of Tumours of the Central Nervous System, we classified CNS tumour into nine categories based on histology, including medulloblastoma, ependymoma, meningioma, ependymoblastoma, astrocytoma, craniopharyngioma, haemangioma, neurinoma, and others. Besides, CNS tumour was further classified based on the anatomic location: brain, spinal cord, peripheral nerve and others.

We further linked subjects to the Statistics Sweden's Total Population Register and Population Housing Census to obtain baseline demographic characteristics which were shown in Table 1. Birth year was shown as born before or after 1980. Birth country was classified into born in Sweden or abroad. Highest education level was modeled as 1-9 years, $10-11$ years and $>11$ years.

The unique individual national identification number was assigned to all the residents living in Sweden for longer than three months, which was replaced by serial numbers to provide anonymity and used to link several registers in this study. 
Table 1 Characteristics of long-term survivors with childhood or adolescent central nervous system tumour and matched controls

\begin{tabular}{|c|c|c|c|c|}
\hline \multirow[t]{2}{*}{ Charateristics } & \multicolumn{2}{|c|}{$\begin{array}{l}\text { Survivors of } \\
\text { CNS tumour }\end{array}$} & \multicolumn{2}{|c|}{$\begin{array}{l}\text { Matched con- } \\
\text { trols }\end{array}$} \\
\hline & No & $\%$ & No & $\%$ \\
\hline Overall & 3264 & 100.0 & 16,320 & 100.0 \\
\hline Total follow up time, person years & 66,600 & & 367,108 & \\
\hline \multicolumn{5}{|l|}{ Gender } \\
\hline Female & 1508 & 46.2 & 7540 & 46.2 \\
\hline Male & 1756 & 53.8 & 8780 & 53.8 \\
\hline \multicolumn{5}{|l|}{ Birth year } \\
\hline$\leq 1980$ & 1593 & 48.8 & 7965 & 48.8 \\
\hline$>1980$ & 1671 & 51.2 & 8355 & 51.2 \\
\hline \multicolumn{5}{|l|}{ Birth country } \\
\hline Sweden & 3133 & 96.0 & 15,665 & 96.0 \\
\hline Others & 131 & 4.0 & 655 & 4.0 \\
\hline \multicolumn{5}{|l|}{ Highest education } \\
\hline $1-9$ years & 563 & 17.3 & 2815 & 17.3 \\
\hline $10-11$ years & 1936 & 59.3 & 9680 & 59.3 \\
\hline $12+$ years & 765 & 23.4 & 3825 & 23.4 \\
\hline \multicolumn{5}{|l|}{ Age at diagnosis } \\
\hline Preschool age (0-4 years old) & 960 & 29.4 & & \\
\hline $\begin{array}{l}\text { Primary school age (5-9 years } \\
\text { old) }\end{array}$ & 746 & 22.9 & & \\
\hline Preadolescent (10-14 years old) & 821 & 25.1 & & \\
\hline Adolescent (15-19 years old) & 737 & 22.6 & & \\
\hline \multicolumn{5}{|l|}{ Year of diagnosis } \\
\hline $1958-1990$ & 1618 & 49.6 & & \\
\hline $1991-2015$ & 1646 & 50.4 & & \\
\hline \multicolumn{5}{|l|}{ Histology } \\
\hline Astrocytoma & 1468 & 45.0 & & \\
\hline Craniopharyngiomas & 175 & 5.3 & & \\
\hline Ependymoma & 176 & 5.4 & & \\
\hline Ependymoblastoma & 38 & 1.1 & & \\
\hline Haemangioma & 57 & 1.7 & & \\
\hline Medulloblastoma & 245 & 7.5 & & \\
\hline Meningioma & 81 & 2.5 & & \\
\hline Neurinoma & 149 & 4.6 & & \\
\hline Others & 875 & 26.9 & & \\
\hline \multicolumn{5}{|l|}{ Location } \\
\hline Brain & 2704 & 82.8 & & \\
\hline Spinal cord & 206 & 6.3 & & \\
\hline Peripheral nerve & 277 & 8.5 & & \\
\hline Others & 77 & 2.4 & & \\
\hline \multicolumn{5}{|l|}{ Follow-up time, years } \\
\hline$\leq 10$ & 936 & 28.7 & & \\
\hline $11-20$ & 842 & 25.8 & & \\
\hline $21-30$ & 660 & 20.2 & & \\
\hline$>30$ & 826 & 25.3 & & \\
\hline
\end{tabular}

CNS central nervous system

\section{Statistical analyses}

Cox proportional hazard model was used to calculate hazard ratios (HRs) and 95\% confidence intervals (CIs) between CNS tumour diagnosis and mortality. Follow-up of CNS tumour survivors were started at the date of five years after the primary diagnosis of CNS tumour, and the matched controls was started at the same date with the corresponding survivors. We censored individuals on the date of death or at the end of the study period (March 2017), whichever came first. The mortality rate was calculated as the number of deaths divided by 1000 person-years of follow-up. We further calculated absolute excess risk (AER) and its 95\% CI, which was defined as the minus of mortality rate in the study population to the mortality rate in the matched controls.

We stratified analyses by gender and age at diagnosis to explore the difference of mortality patterns. In addition, we examined the trends of overall mortality, neoplasm-caused mortality and non-neoplastic causes mortality among long-term survivors who were followed up $\leq 10$ years, 11-20 years, 21-30 years and $>30$ years, respectively (equal to surviving for 5-15 years, 16-25 years, 26-35 years and $>35$ years, respectively). We also calculated HRs and 95\% CIs by comparing the mortality of specific types of CNS tumour to their matched controls.

All analyses were performed using SAS version 9.3 (SAS Institute, Cary, NC).

\section{Results}

A total of 3264 long-term survivors of childhood or adolescent CNS tumour were identified from the Swedish Cancer Registry between 1958 and 2016. After a total of 66,600 person-years of follow-up, 471 patients had died, generating a mortality rate of 7.1 per 1000 person-years. Among 16,320 matched controls, 434 subjects had died after 367,108 person-years of follow-up with a mortality rate of 1.18 per 1000 person-years. Characteristics of long-term survivors of CNS tumour are shown in Table 1. Male survivors $(53.8 \%)$ surpassed female survivors (46.2\%) and $77.4 \%$ of long-term survivors were diagnosed with CNS tumour during childhood ( $<15$ years old). About half of them (48.8\%) were born before 1980 and the majority of patients $(96.0 \%)$ were born in Sweden.

We present the HR and AER among long-term survivors of childhood and adolescent CNS tumour in Table 2. As compared to matched controls, long-term survivors suffered a significantly higher risk of death with a HR of $6.56(95 \%$ CI 5.71-7.53), which led to an excess mortality rate of 5.89 per 1000 person-years (95\% CI 5.03-6.87). The mortality rate was significantly higher for all the cause-specific deaths with an exception of death due to injury, poisoning and 
Table 2 Hazard ratio and absolute excess risk with 95\% CI for all-cause and specific disease mortality among survivors with childhood or adolescent central nervous system tumour and matched controls

\begin{tabular}{|c|c|c|c|c|c|c|c|c|}
\hline \multirow[t]{2}{*}{ Outcomes } & \multicolumn{2}{|c|}{ Number of deaths } & \multicolumn{2}{|c|}{$\begin{array}{l}\text { Mortality rates (per } \\
1000 \text { person-years) }\end{array}$} & \multirow[t]{2}{*}{ HR } & \multirow[t]{2}{*}{$95 \% \mathrm{CI}$} & \multirow[t]{2}{*}{ AER } & \multirow[t]{2}{*}{$95 \% \mathrm{CI}$} \\
\hline & Survivors & $\begin{array}{l}\text { Matched } \\
\text { controls }\end{array}$ & Survivors & $\begin{array}{l}\text { Matched } \\
\text { controls }\end{array}$ & & & & \\
\hline All cause mortality & 471 & 434 & 7.07 & 1.18 & 6.56 & $5.71-7.53$ & 5.89 & $5.03-6.87$ \\
\hline \multicolumn{9}{|l|}{ Specific disease mortality } \\
\hline Malignant neoplasms & 270 & 112 & 4.05 & 0.31 & 15.89 & $12.42-20.32$ & 3.75 & $2.95-4.75$ \\
\hline Infectious and parasitic disease & 6 & 3 & 0.09 & 0.01 & 9.53 & $2.38-38.15$ & 0.08 & $0.01-0.35$ \\
\hline Diseases of the nervous system and sense organ & 18 & 16 & 0.27 & 0.04 & 5.80 & $2.92-11.52$ & 0.23 & $0.09-0.49$ \\
\hline Diseases of the respiratory system & 14 & 16 & 0.21 & 0.04 & 4.81 & $2.29-10.09$ & 0.17 & $0.06-0.39$ \\
\hline Endocrine, nutritional and metabolic diseases & 4 & 11 & 0.06 & 0.03 & 3.90 & $1.05-14.54$ & 0.03 & $0.00-0.16$ \\
\hline Diseases of the digestive system & 8 & 18 & 0.12 & 0.05 & 3.85 & $1.52-9.77$ & 0.07 & $0.00-0.23$ \\
\hline Diseases of the circulatory system & 44 & 64 & 0.66 & 0.17 & 3.74 & $2.51-5.57$ & 0.49 & $0.28-0.80$ \\
\hline $\begin{array}{l}\text { Injury, poisoning and certain other consequences } \\
\text { of external causes }\end{array}$ & 36 & 141 & 0.54 & 0.38 & 1.40 & $0.96-2.03$ & 0.16 & $0.00-0.40$ \\
\hline Others & 37 & 30 & 0.56 & 0.08 & 7.57 & $4.53-12.66$ & 0.47 & $0.26-0.82$ \\
\hline
\end{tabular}

$A E R$ absolute excess risk, $C N S$ central nervous system, $C I$ confidence interval, $H R$ hazard ratio

certain other consequence of external causes. Malignant neoplasms, infectious and parasitic disease, and diseases of the nervous system and sense organ ranked the top three causes related to the increased risk of mortality, generating HRs of 15.89 (95\% CI 12.42-20.32), 9.53 (95\% CI 2.38-38.15) and 5.80 (95\% CI 2.92-11.52), respectively. The top three causes accounted for absolute excess risk were malignant neoplasms (AER 3.75; 95\% CI 2.95-4.75), diseases of the respiratory system (AER 0.49; 95\% CI $0.28-0.80$ ) and diseases of the nervous system and sense organ (AER 0.23; 95\% CI 0.09-0.49).

We present the survival curves according to all-cause mortality, neoplasm-caused mortality and non-neoplastic mortality in Supplementary Fig. 1 (Online only). The difference between survivors and controls was more attributable to neoplasm-caused death in the earlier period of follow-up while the difference was dominated by non-neoplastic death in the latter period. We further explored the trend for allcause mortality, neoplasm-caused mortality and non-neoplastic mortality with the increasing survival time, shown in Fig. 1. The HR significantly declined with the increasing survival time, especially for neoplasm-specific death. During the first 10 years of long-term survivors, the risk of death due to neoplasm was extremely high (HR 122.30), and it dramatically declined for the second 10 years with a HR of 3.30, and a HR of 2.03 for the third 10 years, and a HR of 1.76 for those who were followed more than 30 years. The HR for overall mortality was 13.67 at the first 10 years of follow-up, and then decreased over survival time. But the overall mortality rate was still significantly higher even after 30 years of follow-up (HR 1.80). HR for deaths caused by non-neoplastic diseases was 3.20 for the first 10 years of follow-up and kept declining until followed up for 30 years.

As shown in Fig. 2, analyses stratified by gender found that female survivors experienced an even higher overall mortality with a HR of 8.01 , while the HR was 5.79 for male survivors. For specific causes of death, endocrine, nutritional and metabolic diseases played a predominant role among female survivors (HR 14.22), followed by diseases of digestive system (HR 12.50) and malignant neoplasms (HR 11.46). However, the highest risk of mortality in male survivors was caused by malignant neoplasms (HR 22.92), followed by infectious and parasitic disease (HR 12.12) and other causes (HR 8.00). In Fig. 3, we stratified the analyses based on age at diagnosis. The overall risk of death for survivors aged 0 to 4,5 to 9,10 to 14 , and 15 to 19 years was $8.11,9.29,6.46$, and 4.82 respectively. In terms of mortality patterns, both childhood and adolescent survivors were most likely to die due to malignant neoplasms (HR 22.04 vs. 8.97).

In Table 3, we present the results for specific types of CNS tumour as compared to matched controls. Survivors diagnosed with medulloblastoma were at the highest risk of late mortality with a HR of 17.64 (95\% CI 10.30-30.20) and an excess mortality rate of 14.29 (95\% CI 8.69-23.09) per 1000 person-years. The relative risk of death was followed by ependymoma (HR 9.52) and meningioma (HR 7.93). The excess mortality rate was followed by ependymoma (AER 10.26) and ependymoblastoma (AER 8.84). Stratified analysis by tumour location showed that patients with brain tumour was more strongly associated with a higher risk of late mortality (HR 6.58; AER 6.31). 
Fig. 1 Temporal trends of hazard ratio of all-cause, neoplasmspecific or non-neoplastic mortality among long-term survivors with childhood or adolescent central nervous system tumour with the increasing survival time

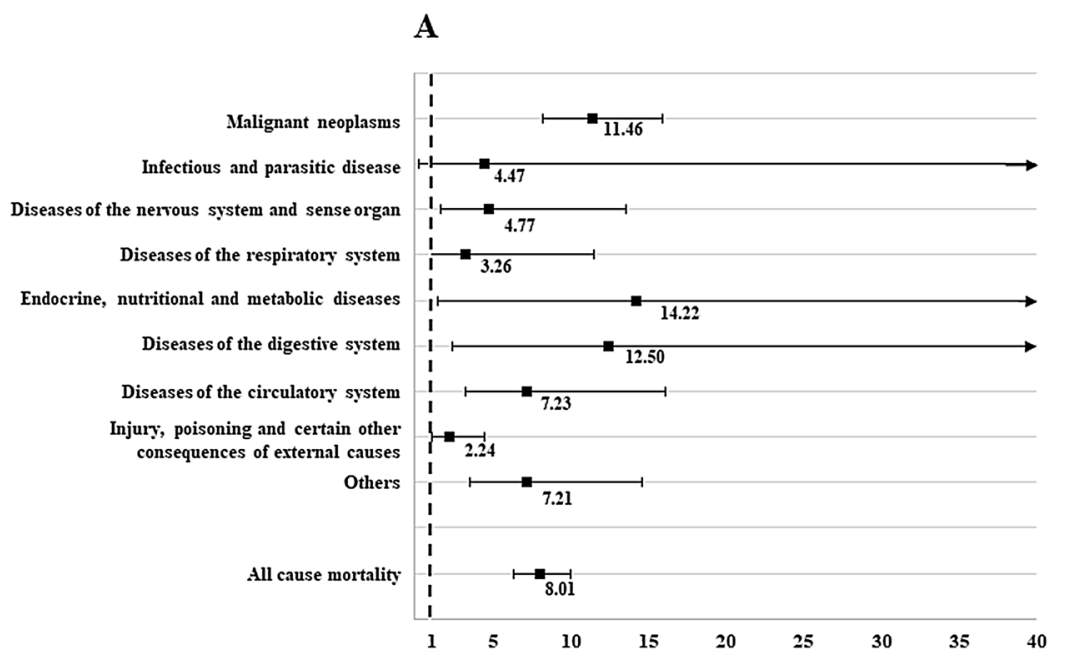

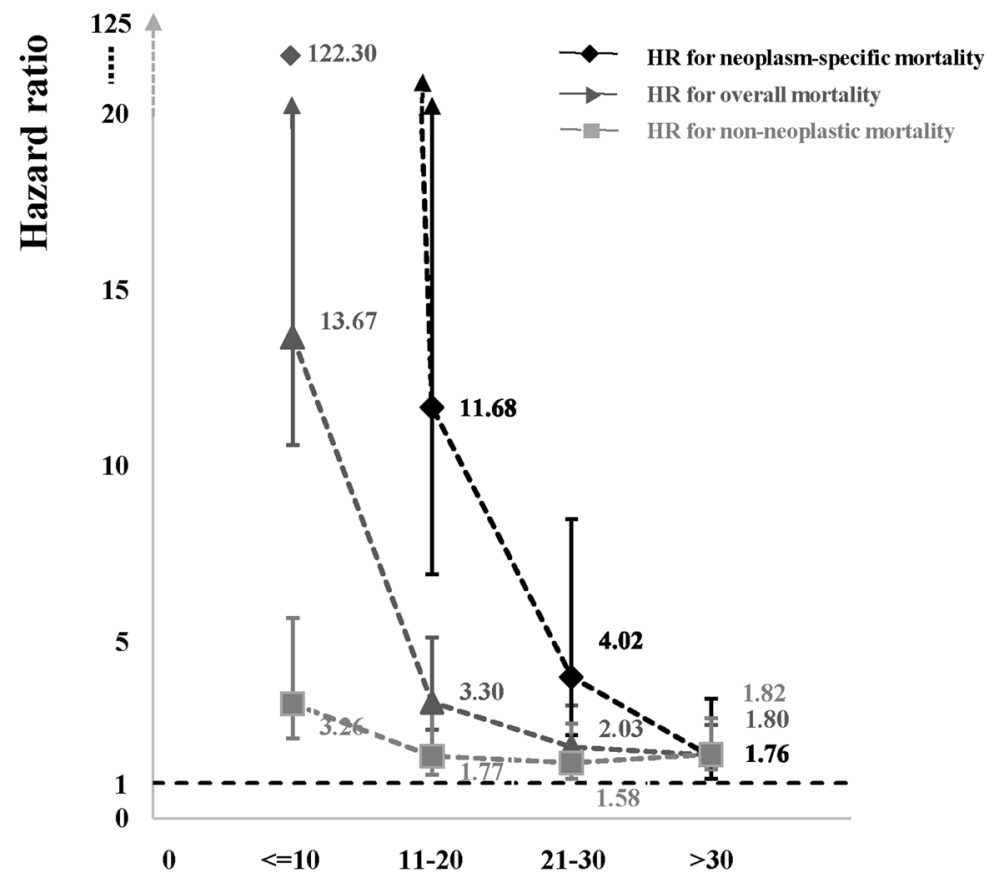

Follow-up time /years

\begin{tabular}{lcccc}
\hline HR (95\%CI) & $<=10$ & $\mathbf{1 1 - 2 0}$ & $\mathbf{2 1 - 3 0}$ & $>\mathbf{3 0}$ \\
\hline Neoplasm-specific mortality & $122.30(57.44-260.40)$ & $11.68(6.92-19.70)$ & $4.02(2.36-6.83)$ & $1.76(1.12-2.76)$ \\
Overall mortality & $13.67(10.59-17.66)$ & $3.30(2.51-4.34)$ & $2.03(1.53-2.70)$ & $1.80(1.43-2.28)$ \\
Non-neoplastic mortality & $3.26(2.27-4.70)$ & $1.77(1.23-2.55)$ & $1.58(1.12-2.23)$ & $1.82(1.38-2.39)$ \\
\hline
\end{tabular}

Fig. 2 Hazard ratio and 95\% confidence interval of all-cause, disease-specific mortality among long-term survivors with childhood or adolescent central nervous system tumour stratified by gender. a Female survivors; $\mathbf{b}$ male survivors

\section{Discussion}

In this nationwide cohort study, which to our best knowledge is the largest study on this topic, we found that
B

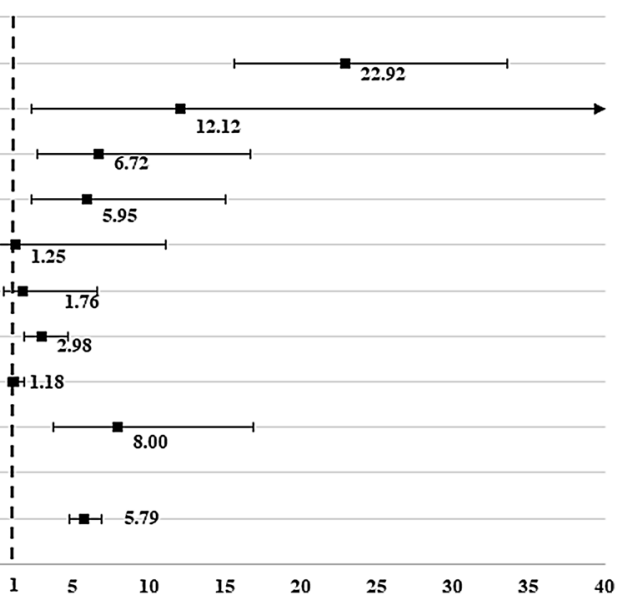

long-term survivors of childhood and adolescent CNS tumour experienced a high risk of death when compared to their matched controls. The overall mortality rate declined with the increasing survival time, but it was still higher even after 30 years of follow-up. Malignant neoplasm 

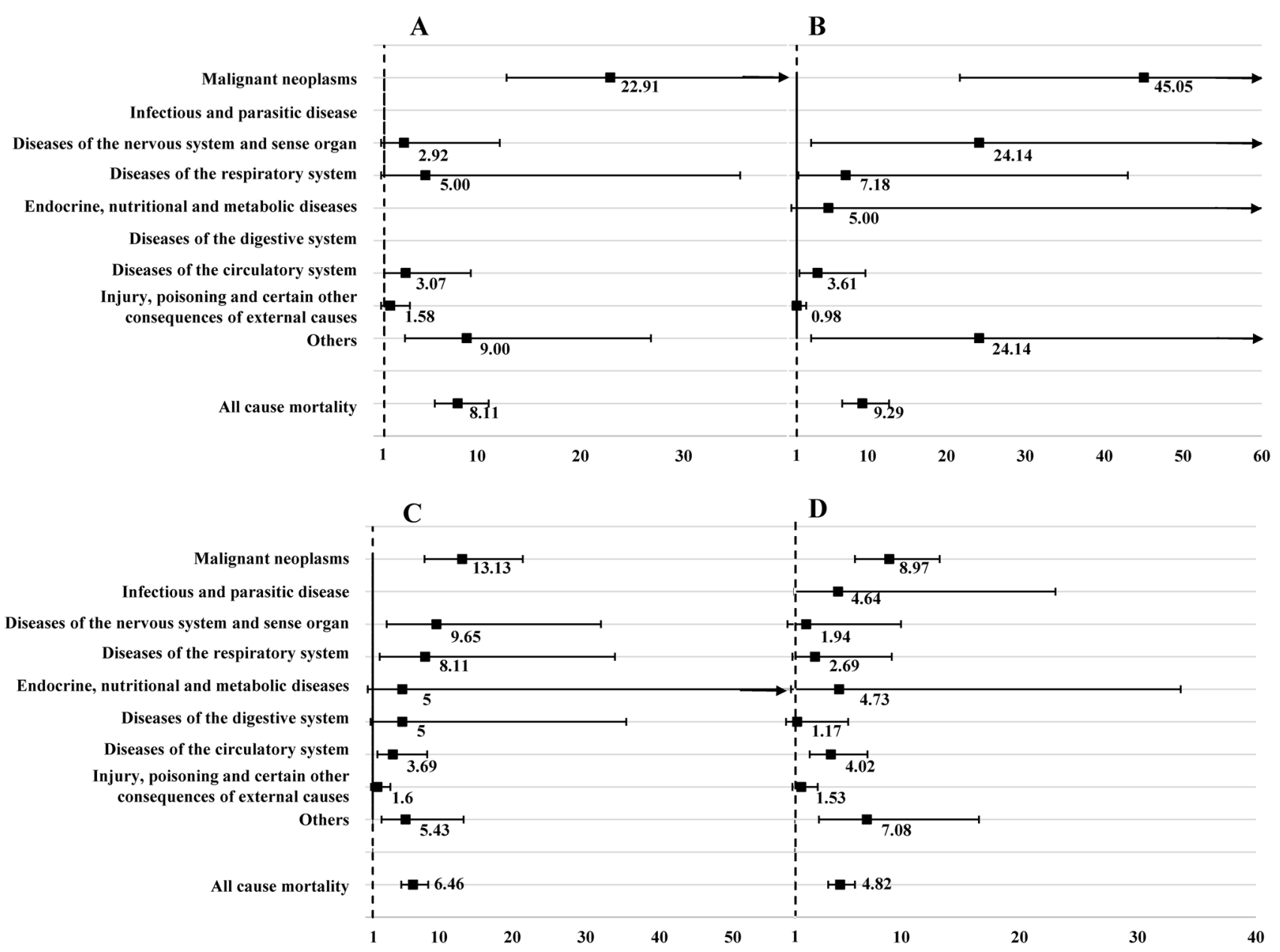

Fig. 3 Hazard ratio and 95\% confidence interval of all-cause, disease-specific mortality among long-term survivors with childhood or adolescent central nervous system tumour stratified by age at diagnosis. a Preschool age; b primary school age; c preadolescent; $\mathbf{d}$ adolescent

was the leading cause of death among these long-term survivors. However, the risk of death due to malignant neoplasm underwent a sharp decline with the increasing of survival time, and it was comparable with death due to non-neoplasm cause after 30 years of follow-up. The late mortality was even more pronounced among female and survivors diagnosed at a younger age as compared to male and adolescent survivors. The risk of death was associated with specific histological types of CNS tumours with the highest risk noted among survivors with medulloblastoma.

In line with previous studies, our study suggested an elevated risk of death in long-term survivors who have ever been diagnosed with CNS tumours in childhood and adolescence even after surviving for more than 35 years when compared with the general population [3-7, 10, 12, 13]. A previous study in British Columbia indicated an excess late mortality in 5-year survivors of childhood and adolescent cancer with a standard mortality ratio of 14.0 [10]. Clinical doctors, in particular family physicians, should be aware of the high risk of late severe effects and late mortality among
CNS tumour survivors who have survived for more than 5 years and were believed to reach a clinical cure. The need of increased awareness is particularly relevant during the first ten years of follow-up in the 5-year survivors. One report from Childhood Cancer Survivor Study (CCSS) suggested that only $18 \%$ of the 8522 long-term survivors with childhood cancer received risk-based and survivor-focused medical care [14]. A survey, which was conducted in the United States and Canada, found that most family physicians (85\%) would be willing to care for childhood cancer survivors, but only $1 \%$ of them would be competent in caring for these patients independently [15]. Due to the lack of longterm follow-up surveillance guidelines, family physicians prefer to ensure care of these survivors in consultation with a cancer centre [15].

In the present study, the increased mortality attributed mostly to malignant neoplasm with an excess mortality rate of 3.75 per 1000 person-years, which was consistent with a few previous studies in long-term survivors of childhood cancer [3-7, 10, 12, 13]. After malignant neoplasm, 
Table 3 Hazard ratio and absolute excess risk with 95\% CI for all-cause among survivors with different types of childhood or adolescent central nervous system tumour and matched controls

\begin{tabular}{|c|c|c|c|c|c|c|c|c|}
\hline \multirow[t]{2}{*}{ Outcomes } & \multicolumn{2}{|c|}{ Number of deaths } & \multicolumn{2}{|c|}{$\begin{array}{l}\text { Mortality rates (per } 1000 \\
\text { person-years) }\end{array}$} & \multirow[t]{2}{*}{ HR } & \multirow[t]{2}{*}{$95 \% \mathrm{CI}$} & \multirow[t]{2}{*}{ AER } & \multirow[t]{2}{*}{$95 \% \mathrm{CI}$} \\
\hline & Survivors & Matched & Survivors & Matched & & & & \\
\hline \multicolumn{9}{|l|}{ Histology } \\
\hline Medulloblastoma & 61 & 27 & 15.36 & 1.07 & 17.64 & $10.30-30.20$ & 14.29 & $8.69-23.09$ \\
\hline Ependymoma & 37 & 23 & 11.47 & 1.21 & 9.52 & $5.47-16.55$ & 10.26 & $5.61-18.10$ \\
\hline Meningioma & 16 & 14 & 10.26 & 1.49 & 7.93 & $3.60-17.49$ & 8.77 & $3.52-19.54$ \\
\hline Ependymoblastoma & 8 & 5 & 9.98 & 1.13 & 7.87 & $2.57-24.06$ & 8.84 & $2.13-29.36$ \\
\hline Astrocytoma & 199 & 188 & 6.35 & 1.10 & 6.23 & $5.05-7.69$ & 5.25 & $4.10-6.65$ \\
\hline Craniopharyngiomas & 38 & 32 & 10.23 & 1.56 & 6.20 & $3.82-10.07$ & 8.67 & $4.84-14.81$ \\
\hline Haemangioma & 5 & 12 & 3.93 & 1.82 & 3.82 & $1.16-12.56$ & 2.12 & $0.00-9.35$ \\
\hline Neurinoma & 19 & 32 & 5.51 & 1.72 & 3.47 & $1.92-6.28$ & 3.79 & $1.40-8.00$ \\
\hline Others & 88 & 101 & 5.10 & 1.09 & 5.27 & $3.90-7.13$ & 4.01 & $3.01-5.34$ \\
\hline \multicolumn{9}{|l|}{ Location } \\
\hline Brain & 412 & 367 & 7.52 & 1.21 & 6.58 & $5.75-7.53$ & 6.31 & $5.48-7.26$ \\
\hline Spinal cord & 30 & 33 & 6.87 & 1.36 & 5.80 & $4.01-8.40$ & 5.50 & $3.36-9.02$ \\
\hline Peripheral nerve & 25 & 32 & 3.88 & 0.93 & 3.14 & $2.10-4.70$ & 2.95 & $1.75-4.99$ \\
\hline Others & 4 & 2 & 3.98 & 0.38 & 4.48 & $1.67-12.01$ & 3.60 & $0.66-19.66$ \\
\hline
\end{tabular}

$A E R$ absolute excess risk, $C N S$ central nervous system, $C I$ confidence interval, $H R$ hazard ratio

long-term survivors of CNS tumour had an increased relative risk of death due to infectious and parasitic disease, diseases of the nervous system and sense organ, and diseases of the respiratory system. Of particular note was that the causes of death changed with the increasing survival time. Mortality due to neoplasm declined sharply, especially during the first 10 years of follow-up. With longer survival time, mortality caused by non-neoplastic diseases was similar as compared to malignant neoplasm (HR 1.82 for non-neoplastic diseases versus 1.76 for malignant neoplasm). The higher risk of death due to non-neoplastic diseases might be caused by tumour treatments in early life [16]. It is thus necessary to keep on monitoring for life of patients who survived over five years with an aim to minimise the excess mortality caused by late effects of tumour diagnosis and treatment.

It is worth pointing out that the risk of death was even more pronounced among female and childhood survivors as compared to male and adolescent survivors. Results from several prior studies reported a high mortality rate among female long-term cancer survivors, indicating that female survivors were at higher hazard of late mortality $[3,4,7,8]$. Furthermore, the causes of death differed between male and female survivors, suggesting that tailored surveillance guidelines are highly needed with a consideration of gender and age at diagnosis of CNS tumour. The highest risk for death among female survivors was caused by endocrine, nutritional and metabolic diseases. Gurney et al. reported that $43 \%$ of adult survivors of childhood brain tumours had previously experienced endocrine dysfunction [17]. Evidence from survivors of childhood cancer suggested that female survivors tend to experience a higher risk of severe thyroid diseases, central precocious puberty, gonadal damage, and obesity [16, 18-20]. The risk of late mortality in childhood survivors was significantly higher than that in adolescent survivors, especially death caused by malignant neoplasm (HR 22.02 vs 8.97). Most previous studies reported the standard mortality ratio (SMR) among long-term survivors with childhood CNS tumours and the SMR ranged between 15.7 in Switzerland, 14.7 in Scotland, 12.9 in United States, and 11.5 in Great Britain [3-5, 7, 9], which suggests that cancer treatments in children had a more sustainable and serious impact on these survivors. Regarding the specific type of CNS tumour, out study found for the first time that long-term survivors with medulloblastoma had a higher risk of late mortality as compared to other types of CNS tumours.

Several strengths of this study should be mentioned. The cohort study design excluded recall bias and minimized selection bias. The accuracy of identification of cancer as well as the death of causes was guaranteed by using the Swedish registers with nationwide coverage and high sensitivity and specificity. The Swedish Cancer Registry was created in 1958 and last updated in 2016; this allowed us to follow these long-term CNS tumour survivors for several decades and to explore the patterns of death. A major limitation of this study was the lack of information on medical treatments, which made it unavailable to explore the association between medical treatments and late mortality pattern. Besides, residual confounding effect could not be totally 
excluded due to the lack of individual-level risk factors, such as dietary factors. However, each patient was randomly matched with cancer-free individuals' conditional on birth year, sex, birth country, and highest education, which was supposed to partly control the potential confounding effect.

In conclusion, our study found a high mortality rate among long-term CNS tumour survivors. Although the increasing risk of death was negatively associated with the increasing survival time, the mortality rate was still higher than the general population even after 30 years of follow-up. The risk of death was even higher among female and childhood survivors, and survivors with medulloblastoma. Our data suggests that surveillance guidelines are highly needed for long-term CNS tumour survivors, and the guidelines should be tailored by gender, age at diagnosis as well as the histological type of CNS tumour to provide personalized and precision recommendations.

Acknowledgements Open access funding provided by Lund University. The authors wish to thank the CPF's science editor Patrick Reilly for his valuable comments on the text.

Author contributions WH, JJ, KS, and JS were responsible for the study concept and design. JS, KS, and JJ obtained funding. KS and JS acquired the data. WH did the statistical analysis and drafted the manuscript, and all authors revised it for important intellectual content.

Funding This work was supported by grants awarded to Dr Jianguang Ji by the Swedish Research Council (2016-02373) and Cancerfonden (2017 CAN2017/340) and Crafoordska stiftelsen, to Dr Kristina Sundquist by the Swedish Research Council (K2012-70X-15428-08-3), to Dr Jan Sundquist by the Swedish Council for Working Life, Social Research (2007-1754), to Jan Sundquist, Kristina Sundquist, and Dr Jianguang Ji by ALF funding from Region Skåne, and to Wuqing Huang by China Scholarship Council (Grant No. 201806380121). The funding agencies had no role in the design and conduct of the study; in the collection, analysis, and interpretation of the data; or in the preparation, review, or approval of the manuscript. The researchers were independent of the funding agencies.

\section{Compliance with ethical standards}

Conflict of interest The authors confirm that there are no conflicts of interest.

Open Access This article is distributed under the terms of the Creative Commons Attribution 4.0 International License (http://creativeco mmons.org/licenses/by/4.0/), which permits unrestricted use, distribution, and reproduction in any medium, provided you give appropriate credit to the original author(s) and the source, provide a link to the Creative Commons license, and indicate if changes were made.

\section{References}

1. Danckert B, Ferlay J, Engholm G, Hansen HL, Johannesen TB, Khan S, Køtlum JE, Ólafsdóttir E, Schmidt LKH, Virtanen A, Storm HH (2019) NORDCAN: cancer incidence, mortality, prevalence and survival in the Nordic countries, Version 8.2. Association of the Nordic Cancer Registries. Danish Cancer Society. https://www.ancr.nu, Accessed 26 March 2019

2. Ward E, DeSantis C, Robbins A, Kohler B (2014) Jemal A (2014) Childhood and adolescent cancer statistics. CA Cancer J Clin 64(2):83-103. https://doi.org/10.3322/caac.21219

3. Brewster DH, Clark D, Hopkins L, Bauer J, Wild SH, Edgar AB, Hamish Wallace W (2013) Subsequent mortality experience in five-year survivors of childhood, adolescent and young adult cancer in Scotland: a population based, retrospective cohort study. Eur J Cancer 49(15):3274-3283. https://doi.org/10.1016/j. ejca.2013.05.004

4. Fidler MM, Reulen RC, Winter DL, Kelly J, Jenkinson HC, Skinner R, Frobisher C, Hawkins MM, British Childhood Cancer Survivor Study Steering Group (2016) Long term cause specific mortality among 34,489 five year survivors of childhood cancer in Great Britain: population based cohort study. BMJ 354:i4351. https://doi.org/10.1136/bmj.i4351

5. Garwicz S, Anderson H, Olsen JH, Winther JF, Sankila R, Langmark F, Tryggvadottir L, Moller TR, Association of the Nordic Cancer R, Nordic Society for Pediatric Hematology O (2012) Late and very late mortality in 5-year survivors of childhood cancer: changing pattern over four decades-experience from the Nordic countries. Int J Cancer 131(7):1659-1666. https://doi. org/10.1002/ijc.27393

6. Reulen RC, Winter DL, Frobisher C, Lancashire ER, Stiller CA, Jenney ME, Skinner R, Stevens MC, Hawkins MM, British Childhood Cancer Survivor Study Steering Group (2010) Long-term cause-specific mortality among survivors of childhood cancer. JAMA 304(2):172-179. https://doi.org/10.1001/jama.2010.923

7. Schindler M, Spycher BD, Ammann RA, Ansari M, Michel G, Kuehni CE, Swiss Paediatric Oncology G (2016) Cause-specific long-term mortality in survivors of childhood cancer in Switzerland: a population-based study. Int J Cancer 139(2):322-333. https ://doi.org/10.1002/ijc.30080

8. Cardous-Ubbink MC, Heinen RC, Langeveld NE, Bakker PJ, Voute PA, Caron HN, van Leeuwen FE (2004) Long-term causespecific mortality among five-year survivors of childhood cancer. Pediatr Blood Cancer 42(7):563-573. https://doi.org/10.1002/ pbc. 20028

9. Armstrong GT, Liu Q, Yasui Y, Neglia JP, Leisenring W, Robison LL, Mertens AC (2009) Late mortality among 5-year survivors of childhood cancer: a summary from the Childhood Cancer Survivor Study. J Clin Oncol 27(14):2328-2338. https://doi. org/10.1200/JCO.2008.21.1425

10. MacArthur AC, Spinelli JJ, Rogers PC, Goddard KJ, Abanto ZU, McBride ML (2007) Mortality among 5-year survivors of cancer diagnosed during childhood or adolescence in British Columbia, Canada. Pediatr Blood Cancer 48(4):460-467. https://doi. org/10.1002/pbc. 20922

11. Ji J, Sundquist K, Sundquist J, Hemminki K (2012) Comparability of cancer identification among death registry, cancer registry and hospital discharge registry. Int J Cancer 131(9):2085-2093. https ://doi.org/10.1002/ijc.27462

12. Karalexi MA, Papathoma P, Thomopoulos TP, Ryzhov A, Zborovskaya A, Dimitrova N, Zivkovic S, Eser S, Antunes L, Sekerija M, Zagar T, Bastos J, Demetriou A, Agius D, Cozma R, Coza D, Bouka E, Dessypris N, Belechri M, Dana H, Hatzipantelis E, Papakonstantinou E, Polychronopoulou S, Pourtsidis A, Stiakaki E, Chatziioannou A, Manolitsi K, Orphanidis G, Papadopoulos S, Papathanasiou M, Patsouris E, Sgouros S, Zountsas B, Moschovi M, Steliarova-Foucher E, Petridou ET (2015) Childhood central nervous system tumour mortality and survival in Southern and Eastern Europe (1983-2014): gaps persist across 14 cancer registries. Eur J Cancer 51(17):2665-2677. https://doi.org/10.1016/j. ejca.2015.08.018 
13. Armstrong GT, Chen Y, Yasui Y, Leisenring W, Gibson TM, Mertens AC, Stovall M, Oeffinger KC, Bhatia S, Krull KR, Nathan PC, Neglia JP, Green DM, Hudson MM, Robison LL (2016) Reduction in late mortality among 5-year survivors of childhood cancer. N Engl J Med 374(9):833-842. https://doi. org/10.1056/NEJMoa1510795

14. Nathan PC, Greenberg ML, Ness KK, Hudson MM, Mertens AC, Mahoney MC, Gurney JG, Donaldson SS, Leisenring WM, Robison LL, Oeffinger KC (2008) Medical care in long-term survivors of childhood cancer: a report from the childhood cancer survivor study. J Clin Oncol 26(27):4401-4409. https://doi.org/10.1200/ JCO.2008.16.9607

15. Nathan PC, Daugherty CK, Wroblewski KE, Kigin ML, Stewart TV, Hlubocky FJ, Grunfeld E, Del Giudice ME, Ward LA, Galliher JM, Oeffinger KC, Henderson TO (2013) Family physician preferences and knowledge gaps regarding the care of adolescent and young adult survivors of childhood cancer. J Cancer Surviv 7(3):275-282. https://doi.org/10.1007/s11764-013-0271-0

16. Roddy E, Mueller S (2016) Late effects of treatment of pediatric central nervous system tumors. J Child Neurol 31(2):237-254. https://doi.org/10.1177/0883073815587944

17. Gurney JG, Kadan-Lottick NS, Packer RJ, Neglia JP, Sklar CA, Punyko JA, Stovall M, Yasui Y, Nicholson HS, Wolden S, McNeil DE, Mertens AC, Robison LL, Childhood Cancer Survivor Study (2003) Endocrine and cardiovascular late effects among adult survivors of childhood brain tumors: childhood cancer survivor study. Cancer 97(3):663-673. https://doi.org/10.1002/cncr.11095

18. Lustig RH, Post SR, Srivannaboon K, Rose SR, Danish RK, Burghen GA, Xiong X, Wu S, Merchant TE (2003) Risk factors for the development of obesity in children surviving brain tumors. J Clin Endocrinol Metab 88(2):611-616. https://doi.org/10.1210/ jc.2002-021180

19. Bhatti P, Veiga LH, Ronckers CM, Sigurdson AJ, Stovall M, Smith SA, Weathers R, Leisenring W, Mertens AC, Hammond S, Friedman DL, Neglia JP, Meadows AT, Donaldson SS, Sklar CA, Robison LL, Inskip PD (2010) Risk of second primary thyroid cancer after radiotherapy for a childhood cancer in a large cohort study: an update from the childhood cancer survivor study. Radiat Res 174(6):741-752. https://doi.org/10.1667/RR2240.1

20. Rose SR, Horne VE, Howell J, Lawson SA, Rutter MM, Trotman GE, Corathers SD (2016) Late endocrine effects of childhood cancer. Nat Rev Endocrinol 12(6):319-336. https://doi.org/10.1038/ nrendo. 2016.45

Publisher's Note Springer Nature remains neutral with regard to jurisdictional claims in published maps and institutional affiliations. 